\title{
Update on new technologies in digital mammography
}

This article was published in the following Dove Press journal:

International Journal of Women's Health

14 August 2014

Number of times this article has been viewed

\author{
Stephanie K Patterson \\ Marilyn A Roubidoux \\ Division of Breast Imaging, \\ Department of Radiology, \\ University of Michigan Health \\ System, Ann Arbor, MI, USA
}

Correspondence: Stephanie K Patterson Division of Breast Imaging, Department of Radiology, University of Michigan Health System, C404 Med Inn Building SPC 5842, 1500 East Medical Center Drive, Ann Arbor, MI 48I09, USA

Tel +l 7349364355

Fax + I 7342325877

Email spatters@umich.edu
Abstract: Despite controversy regarding mammography's efficacy, it continues to be the most commonly used breast cancer-screening modality. With the development of digital mammography, some improved benefit has been shown in women with dense breast tissue. However, the density of breast tissue continues to limit the sensitivity of conventional mammography. We discuss the development of some derivative digital technologies, primarily digital breast tomosynthesis, and their strengths, weaknesses, and potential patient impact.

Keywords: screening mammography, breast cancer, contrast media, digital breast tomosynthesis

\section{Introduction}

Breast cancer is the most common cancer worldwide among women, with nearly 1.7 million new cases in 2012. The highest incidence rates are in Europe and North America, and by country are highest in Belgium, Denmark, and France. ${ }^{1}$ Breast cancer mortality has decreased in some parts of the world, with screening mammography associated with an up-to-50\% reduction in mortality rate. ${ }^{2}$ Although there has been controversy about mammogram screening, it remains the most commonly performed procedure for breast cancer detection.,

The results of the Digital Mammography Imaging Screening Trial (DMIST) proved digital mammography (DM) was as efficacious as screen-film mammography (SFM). ${ }^{5}$ As such, most of the mammography units in the US are now digital. DM has shown some advantages over the older SFM. DM is less likely to be lost or damaged, and has slightly higher sensitivity than SFM. ${ }^{5}$ However, despite evidence from DMIST that DM offers some improved benefit in women with dense breast tissue, this remains a limitation of conventional mammography in general. ${ }^{5,6}$ Breast cancers will have the same density as surrounding tissue, and can be obscured by overlapping tissue. ${ }^{7,8}$ With tumors potentially obscured by overlapping tissue in two-dimensional (2-D) conventional mammography, a 3-D procedure, such as tomosynthesis, may help solve this problem. ${ }^{7}$ Also, there is hope that the use of intravascular contrast material with DM will take advantage of malignant neovascularity to enhance tumor detection.

This article reflects on these technologies in mammographic imaging, current uses, and potential patient impact. Previous reviews of tomosynthesis ${ }^{9-13}$ have summarized technical developments and the promising early results of small digital breast tomosynthesis (DBT)-reader studies using selected tomosynthesis cases. We add in this review newer prospective population-screening trials from Oslo, Italy, and Australia, which provided a larger amount of data and more definitive results acquired from clinical 
settings. ${ }^{14-17}$ The newest developments in solving the challenge of radiation exposure in tomosynthesis are presented. Furthermore, this review will address a wider audience than radiologists, to inform those of any medical specialty hoping to learn about developments in mammography.

\section{Conventional mammography}

SFM has been in use for over 30 years, and in the last 10 years has been replaced in most practices in the US by full-field DM. ${ }^{18}$ This advance enables viewing and manipulation of DM images on computer workstations. DM has the advantage of separating image acquisition from image display and storage. With these steps separated, each can be potentially optimized. ${ }^{19} \mathrm{DM}$ is similar to SFM in that both are performed with two views of each breast in screening mammography, a compromise between keeping radiation levels low yet imaging the majority of the breast tissue. The two views are called 2-D mammography, and "2-D" is a common abbreviation for two-view DM. ${ }^{9}$ Radiation dose is a concern, given that mammography is a screening examination performed on millions of women potentially every year. The DM systems used in the DMIST trial were shown to have had a $22 \%$ lower mean glandular dose than SFM per acquired view. ${ }^{20}$ Dose parameters reported for DMIST were for state-of-the-art equipment used during the trial, and many of the digital systems have been refined since, and performance may have improved. ${ }^{20-23}$ A specific digital system using slot scanning with a photoncounting detector that eliminates stray or scatter radiation and improves noise reduction and image quality has been found to reduce doses by $40 \%-60 \%, 24,25$ and has shown the lowest mean glandular dose in clinical screening settings in Europe ${ }^{26}$ Indeed, it was found in a dose survey of the Irish breast-screening program that the lower dose resulted from the use of DM systems, and the photon-counting system accounted for $25 \%$ of mammography units in Ireland. ${ }^{27}$ Clinical performance for this system is comparable to other DM systems in screening, ${ }^{28}$ and has not been shown to be inferior in radiologist performance..$^{25}$

One limitation of both SFM and DM is false positives (recall for additional imaging). Women have been recalled for additional imaging from the earliest days of mammogram screening. Since screening mammography is performed on normal asymptomatic women, minimizing harm is important. ${ }^{3,4}$ The false-positive rate of mammography is one of the recurrent criticisms of mammography., In the US, up to $10 \%$ of screened women are recalled for further mammogram views, ultrasound imaging, and/or biopsies, and most of these women do not have cancer. ${ }^{4,5,29}$ Screening mammography cannot fully assess all abnormalities on the basis of the two routine views. Recalls are necessary, because a possible lesion needs to be distinguished from a true lesion, but recalls can also lead to false-positive biopsies. These evaluations are typically time-consuming for the radiologist and patient, and stressful and inconvenient for the patient. Nonetheless, recall improves breast cancer detection, and a balance is sought between increased sensitivity and improved specificity. ${ }^{29}$ Recall rates in the US are about twofold higher than in Europe, with guidelines in the US at overall $<10 \%$, compared to guidelines in Europe of $3 \%-7 \%(<5 \%) .{ }^{20}$ If the additional views for evaluation of abnormal screening mammograms could be reduced, this would be advantageous to patients, referring physicians, and radiologists.

Another limitation of SFM and DM is sensitivity in cancer detection. Sensitivity on average is about $70 \%{ }^{5}$ The problem of false-positive mammogram findings and missed lesions is caused by the overlapping tissue in 2-D images. ${ }^{7,8}$ Abnormalities may be hidden in dense fibroglandular tissue, and the malignant features of cancer may be obscured. The breast is composed of combinations of dense fibroglandular tissue and fat. The American College of Radiology Breast Imaging Reporting and Data System describes four breast parenchymal patterns used in mammography reports, with "fatty" having the least amount of fibroglandular tissue and "extremely dense" having the most (Figure 1). ${ }^{30}$ The number of women with dense breast tissue is not insignificant. Over half of women younger than 50 years have what is considered dense breast tissue, and a third of women over 50 years. ${ }^{31}$ In women with the densest breasts, the sensitivity of mammography may be as low as $30 \%-48 \%,{ }^{32,33}$ and has been found to be a major risk factor for interval cancers. ${ }^{32}$ Women with mammographic density in $75 \%$ or more of the breast have been shown to have an increased risk of breast cancer, either detected by screening or less than 12 months after a negative screening mammogram (interval cancer), ${ }^{34}$ and the risk was found to be greater in younger women. ${ }^{34}$ It is not known to what extent the increased risk of interval cancer is due to masking of cancer from dense tissue or to rapid growth of tumors in dense tissue..$^{32,35,36}$

\section{Digital breast tomosynthesis}

DBT also uses X-rays like conventional mammography, but creates image slices of a tissue volume. The slices are thin, and each is seen as a $1 \mathrm{~mm}$ plane in sharp focus, with the tissue above and below a plane appearing out of focus. The thin slices decrease the problem of confusing overlapping tissue..$^{10}$ DBT is a mammography-based technique 

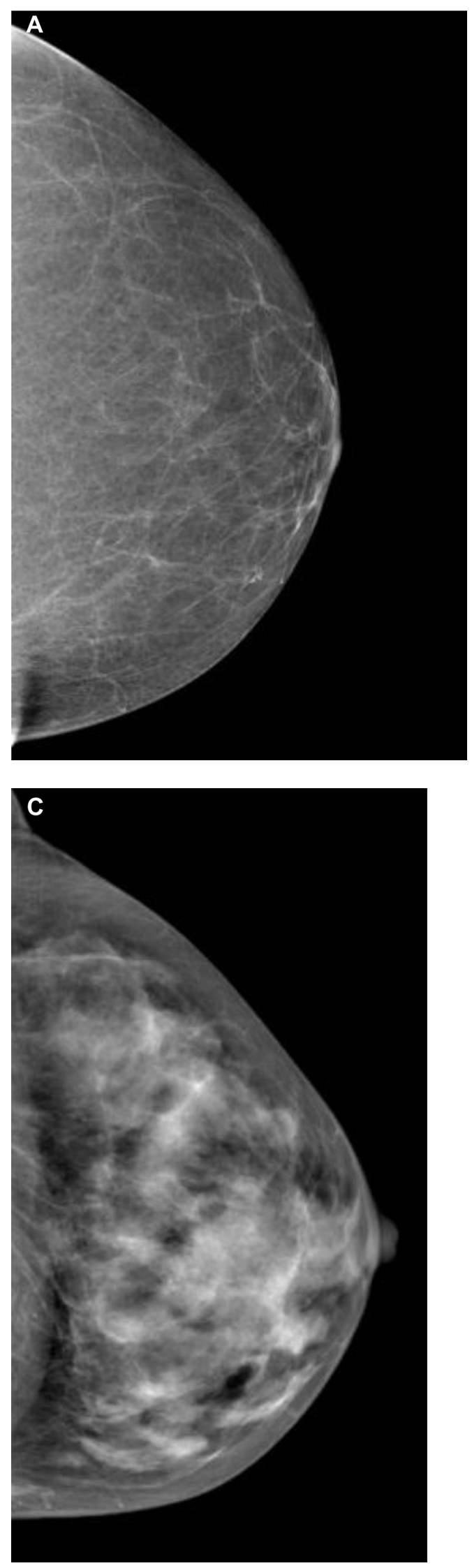

Figure I The four breast parenchymal patterns.

Notes: (A) Fatty; (B) scattered; (C) heterogeneously dense; (D) extremely dense.
B
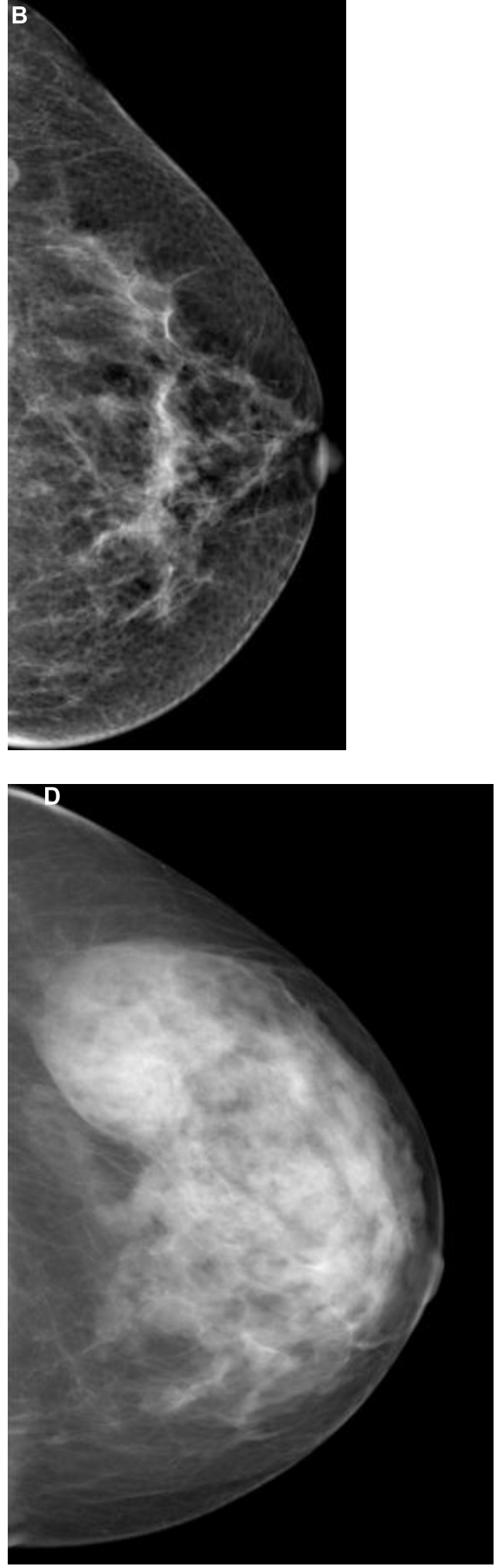
using breast compression similar to 2-D DM, but obtains multiple low-dose images using a moving X-ray tube head rotating across the breast in an arc of $15 \%-50 \%$ (Figure 2)..$^{9,10,37}$ The time varies from about 5 to 25 seconds depending on manufacturer differences. ${ }^{10}$ The image data are used to reconstruct thin tissue slices, such as are seen in computed tomography scans. ${ }^{38}$ Typically, the two conventional views (craniocaudal and mediolateral oblique) are done of each breast of a single breast compression per view. The same anatomy of conventional mammograms is more clearly defined with DBT, with the breast anatomy separated into different tissue planes (Figure 3). DBT is therefore called quasi-3-D technology because it differentiates tissues in slices. ${ }^{37,38}$ Total radiation exposure varies by breast density and thickness, but overall DBT radiation exposure is approximately the same as that of SFM or DM., ${ }^{9,39}$ Since the system is a modified DM unit, DBT images can be obtained in any of the usual mammogram views or planes. ${ }^{10}$ Compression of the breast for tomosynthesis is similar to that of conventional mammography. ${ }^{10}$ Compression maximizes image quality, decreases patient motion, and decreases radiation dose, but is somewhat painful. ${ }^{40}$ However, since the problem of tissue overlap is improved by DBT, some reduction of compression is possible, improving patient comfort. ${ }^{40}$ The feasibility of using tomosynthesis was studied over 10 years ago, ${ }^{38}$ with US Food and Drug Administration (FDA) approval for a commercial system obtained in 2012. ${ }^{41}$ DBT can be used for screening (two views, asymptomatic patients) and diagnostic (multiple views in symptomatic patients) mammography. ${ }^{41,42}$ It has all the advantages of DM, such as fewer artifacts, consistent quality, and digital image processing. ${ }^{9,10}$

There is emerging evidence that adding DBT to standard mammography increases mammogram accuracy. ${ }^{12,13,43}$

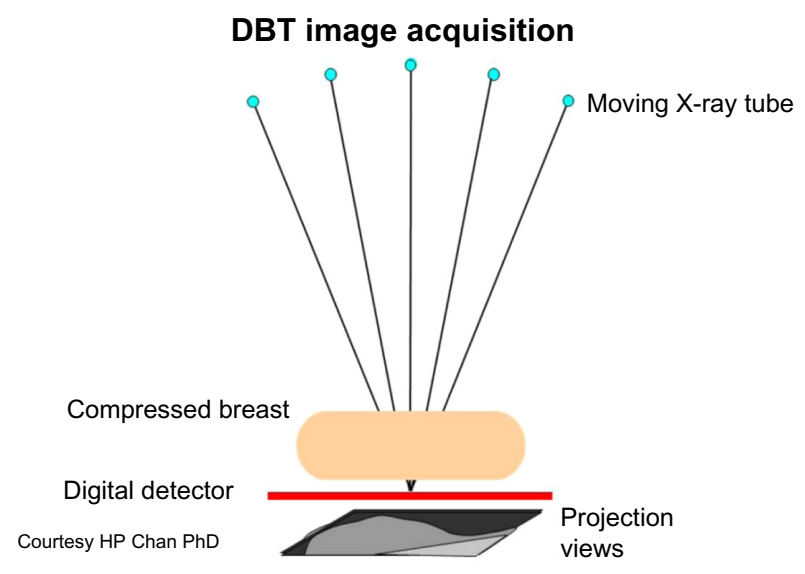

Figure 2 Diagram of the digital breast tomosynthesis (DBT) system.
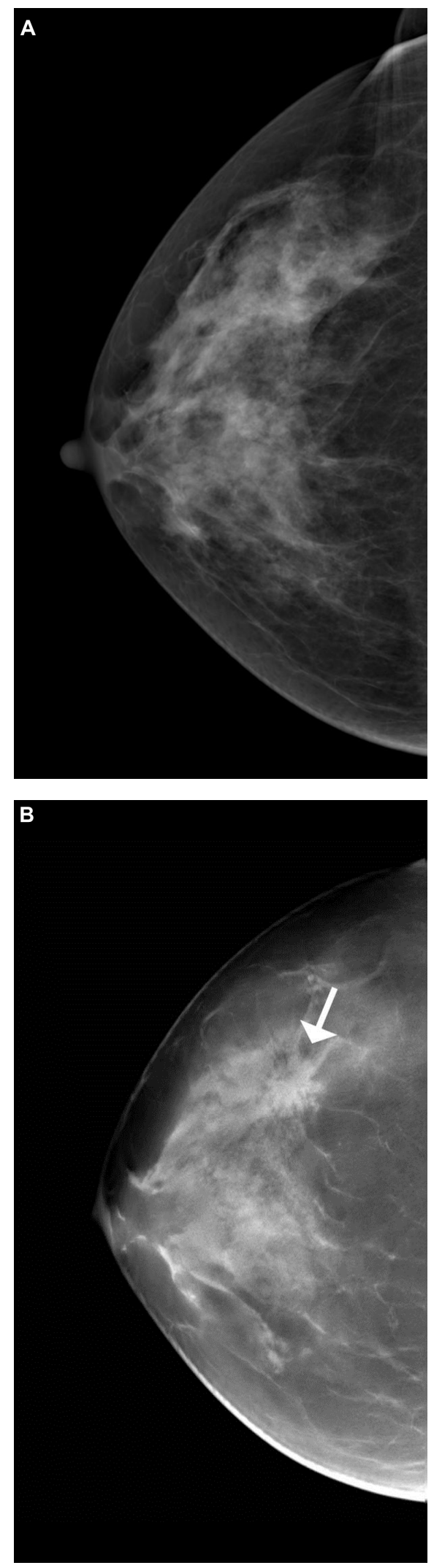

Figure 3 Cancer more evident with tomosynthesis.

Notes: (A) Craniocaudal view of screening digital mammogram. No abnormality is evident. (B) Digital breast tomosynthesis slice of the same patient, in the same position, depicts a spiculated mass in central breast not evident in the screening mammogram view. Proven invasive ductal carcinoma (arrow). 
Limited studies in cancer-enriched groups demonstrated the potential to decrease recall rates and increase cancer detection. ${ }^{9,10,13,43,44}$ Studies were done by acquiring both conventional mammogram views and at the same time DBT views. These were done by exposing the patient twice, and thus resulted in a radiation dose about twice that of mammography alone, but nonetheless below the limits set by the Mammography Quality Standards Act (MQSA). ${ }^{15,39,45}$ A recent population-based prospective clinical trial (Oslo Trial) studied the 50- to 69-year age group with biennial screening, in a single institution with a single group of radiologists, and 12,631 women participating. As in some of the early small studies, the partial results reported that by integrating 2-D and 3-D (ie, DM + DBT) mammography screening, there was a $40 \%$ higher invasive cancerdetection rate compared to DM screening alone. ${ }^{15}$ Another population-based prospective study has reported partial results of 7,292 screened women who similarly had DBT added to DM (STORM [Screening with Tomosynthesis OR Mammography]), and reported that cancer detection rose $34 \%$ and false-positive recalls could decrease by $17 \%$ without missing any cancers. ${ }^{45}$ The additional cancers detected were found in all breast densities, from fatty to dense. The partial results of these clinical trials were still considered small and not adequate to determine which subgroups would benefit most by adding DBT to DM. ${ }^{46}$ Subsequent additional analyses by subgroups reported that centers with high rates of false positives would benefit most from DBT, and that greater accuracy results from adding DBT to DM than from double-reading by DM alone..$^{14,16,17}$ Although using DM with DBT doubles the radiation dose in screening, it has been considered necessary for detection and characterization of calcifications, a potential sign of ductal carcinoma in situ, and additionally to enable orientation of DBT findings when comparing with prior mammograms..$^{47,48}$

The research studies are promising, indicating that DBT is addressing some of the long-standing criticisms of conventional mammography. The addition of DBT to DM (ie, standard 2-D mammography) improves the accuracy of interpretation of mammograms. ${ }^{13,15}$ As discussed earlier, findings questioned on conventional mammography, such as possible masses, are subsequently found on additional imaging to be overlapping glandular tissue. These structures are more easily recognized to be normal on DBT, because only one thin plane of tissue is seen, diminishing confusing overlap. Common benign masses, such as cysts and fibroadenomas, may be more evident as benign masses, because the margins are better seen., ${ }^{7,37}$ The DBT data suggest that not only is there a reduction in recall rate with $\mathrm{DBT}^{49}$ but also that DBT can more clearly depict benign findings than routine screening views (such as lymph nodes or skin calcifications), diminishing the need for recall for additional imaging. Reducing recall rates diminishes the so-called potential harm of recalling normal patients and decreasing the number of false-positive biopsies. In all of the early and most recent studies in both Europe and the US, the recall rate for most radiologists was reduced when adding DBT to DM, despite the already much lower recall rates in Europe compared to the US..$^{15,29,37,45,49}$ DBT appears to increase cancer detection, and the additional cancers detected are invasive malignancies missed by conventional mammography. ${ }^{15}$ Ductal carcinoma in situ, a currently a controversial histologic abnormality versus an early breast cancer, is not more frequent with DBT. ${ }^{15}$ Although DBT will help reveal more cancers in women, it will not detect all cancers. ${ }^{50}$

DBT shows promise in demonstrating the same or higher accuracy as digital spot-compression mammography. ${ }^{51}$ Therefore, DBT alone can also eliminate the need for additional mammogram images in many cases of abnormal mammograms, as well as send patients directly to ultrasound without further mammography. DBT also may decrease the necessity to perform extra mammogram views to identify the exact location of a breast lesion. Radiation dose and patient comfort would benefit if supplementary mammogram views were no longer necessary. Also, with the overall need for compression decreased for tomosynthesis, some studies found that DBT can be done with more patient satisfaction, because up to $50 \%$ less compression than DM can potentially be applied, with no loss in diagnostic capability ${ }^{40}$ For all these reasons, as well as time savings, DBT benefits the patient and radiologist, with improved efficiency in detection and characterizing abnormalities. This also translates into less stress for the patient when there is a decrease in the amount of additional imaging necessary for determining when a lesion is benign versus suspicious. Traditional methods of mammogram workup of abnormalities may improve with the implementation of DBT.

The limitations of DBT are the radiation dose, cost, and work flow. The radiation dose for the combined examination of conventional mammography and DBT is slightly more than twice the dose of mammography alone, because combining both DBT and DM delivers double the radiation dose to the breast. Although this is lower than MQSA limits, radiation has to be considered with the possibility of screening millions of women each year with double the 
radiation dose. ${ }^{39,52}$ To solve this problem, synthetically reconstructed 2-D images can be made from the DBT data, eliminating the need for double exposures. ${ }^{53}$ This eliminates the need to do an exposure for a DM, and also drops the radiation dose to that of conventional mammography. The most recent studies of these synthesized images demonstrated similar accuracy as those of conventional DM, and FDA approval was obtained in the US for the vendor Hologic. ${ }^{48,54}$ Therefore, potentially there will no longer be a need for radiation exposure to obtain 2-D images, and the dose for DBT will fall down to that of conventional mammography. ${ }^{37,54}$

Radiologist-interpretation time is longer for DM + DBT than for DM alone. ${ }^{15}$ This is because a routine mammogram is four images, whereas a DBT can be 200 images or more per patient. Longer interpretation times may be offset by the decreased recall rates and decreased need for additional views. ${ }^{37}$ It is also uncertain how DBT use would be similar or different among radiologists with varying practice patterns and expertise. ${ }^{37}$ The cost of a DBT system is substantially greater than that of a DM system, and also has the expense of digital storage for the large file sizes of DBT. However, compared with breast magnetic resonance imaging (MRI), DBT is a relatively low-cost innovation. In addition, if DBT reduces recall rates, cost savings may result from fewer biopsies and recalls.

At present, DBT is undergoing further technological changes and is a focus of clinical research trials under way or nearing completion. Further optimizing of imaging parameters continues. Large population studies are in progress, and in addition to those already mentioned, there is the Malmö trial, a UK trial, and a Yale study. ${ }^{12}$ A clinical trial is planned in North America by the American College of Radiology Imaging Network to compare DM to DBT (T-MIST [Tomosynthesis Mammographic Imaging Screening Trial]) in a multiple-vendor, multisite study. Its true performance may become more obvious when it has been integrated into such additional population screenings.

Incorporating DBT with other modalities is also being studied, as well as contrast-enhanced tomosynthesis, that could provide an MRI-like study while being simpler to perform and of much lower cost. Automated breast ultrasound with DBT is also evolving, which may be very promising for screening dense breasts. Computer-assisted detection, used routinely in conventional mammography to increase sensitivity, is not yet incorporated into DBT but appears feasible, ${ }^{55}$ and may assist in improving detection of subtle lesions. ${ }^{37}$

\section{Contrast-enhanced digital mammography}

Investigators have evaluated the combination of DM with intravenous contrast enhancement to obtain more functional information from the neovascularity found in malignant tumors. Two methods described have been temporal contrast-enhanced DM (CEDM) and dual-energy CEDM. With CEDM, a DM unit has been modified to maximize the sensitivity of the unit to low concentrations of iodine contrast by increasing the voltage. The breast is in compression in a standard projection. A mask image is obtained, and following the injection of contrast, sequential or temporal images are then obtained. ${ }^{56}$ The examination takes approximately 15 minutes, and the total dose is similar to a conventional single-view mammogram.

In dual-energy CEDM, the DM unit is adapted to generate high energy exposures for energies above the energy absorption of iodine (K-edge), taking advantage of the differences in X-ray attenuation through materials of different composition. ${ }^{56}$ Contrast is injected with the breast in compression, and two paired exposures are obtained: one set at low energy and one at high energy. This technique tends to limit problems with patient motion, as the patient is not in compression as long as with CEDM, and two views of each breast are obtained and combined to enhance contrast-uptake areas. ${ }^{56}$

The use of contrast medium takes advantage of mapping abnormal blood flow, as does MRI. Early evaluation of the feasibility of the use of contrast medium with DM revealed $80 \%$ of pathologically proven breast carcinomas were enhanced, ${ }^{57,58}$ with excellent correlation between the size of enhancement and the histologic size of tumors. ${ }^{58}$ This technique may be particularly useful in patients with dense breast tissue. ${ }^{57-59}$ High sensitivity has also been found with contrast-enhanced dual-energy techniques, with sensitivities between $86 \%-96 \%,{ }^{60-62}$ as well as with contrast use with DBT. ${ }^{63,64}$ Promising results evaluating the feasibility of contrast-enhanced DBT has been shown in one small study ${ }^{64}$ Jochelson et al demonstrated dual-energy CEDM was comparable to MRI for the depiction of the index tumor in patients with known breast cancer, with each identifying $96 \%$ of cancers, and dual-energy CEDM depicted additional cancers in the breast with better specificity. ${ }^{62}$

Potential clinical applications of CEDM include not only detecting mammographically occult cancers in dense breast tissue, but also like MRI help to determine the local extent of disease, or assessment of residual or recurrent disease. The potential advantages over MRI are shorter examination time and ability to perform this exam at the same time as DM, 
image registration allowing easy comparison to conventional mammography, and preoperative guidance for biopsy if only seen with mammography. ${ }^{56}$

\section{Summary}

Mammography continues to be the most efficacious breast cancer-screening modality. Further developments in optimizing imaging parameters and continued improvements in decreasing radiation exposure are ongoing in DM. DBT is proving to address some of the limitations of conventional mammography, with improved cancer detection, fewer false positives, and lower recall rates. The true performance of DBT remains to be determined when the results of more large-population trials have concluded.

\section{Disclosure}

The authors report no conflicts of interest in this work.

\section{References}

1. World Health Organization International Agency for Research on Cancer. GLOBOCAN 2012: Estimated cancer incidence, mortality and prevalence worldwide in 2012. Available from: http://globocan.iarc.fr/ Pages/fact_sheets_cancer.aspx. Accessed May 23, 2014.

2. Nickson C, Mason KE, English DR, Kavanagh AM. Mammographic screening and breast cancer mortality: a case-control study and meta-analysis. Cancer Epidemiol Biomarkers Prev. 2012;21(9): 1479-1488.

3. Bleyer A, Welch HG. Effect of three decades of screening mammography on breast-cancer incidence. N Engl J Med. 2012;367(21):1998-2005.

4. Welch HG, Passow HJ. Quantifying the benefits and harms of screening mammography. JAMA Intern Med. 2014;174(3):448-454.

5. Pisano ED, Gatsonis C, Hendrick E, et al. Diagnostic performance of digital versus film mammography for breast-cancer screening. $N$ Engl J Med. 2005;353(17):1773-1783.

6. Bick U, Diekmann F. Digital mammography: what do we and what don't we know? Eur Radiol. 2007;17(8):1931-1942.

7. Helvie MA. Digital mammography imaging: breast tomosynthesis and advanced applications. Radiol Clin North Am. 2010;48(5):917-929.

8. Bae MS, Moon WK, Chang JM, et al. Breast cancer detected with screening US: reasons for nondetection at mammography. Radiology. 2014;270(2):369-377.

9. Alakhras M, Bourne R, Rickard M, Ng KH, Pietrzyk M, Brennan PC. Digital tomosynthesis: a new future for breast imaging? Clin Radiol. 2013;68(5):e225-e236.

10. Baker JA, Lo JY. Breast tomosynthesis: state-of-the-art and review of the literature. Acad Radiol. 2011;18(10):1298-1310.

11. Drukteinis JS, Mooney BP, Flowers CI, Gatenby RA. Beyond mammography: new frontiers in breast cancer screening. Am J Med 2013;126(6):472-479.

12. Houssami N, Skaane P. Overview of the evidence on digital breast tomosynthesis in breast cancer detection. Breast. 2013;22(2):101-108.

13. Lei J, Yang P, Zhang L, Wang Y, Yang K. Diagnostic accuracy of digital breast tomosynthesis versus digital mammography for benign and malignant lesions in breasts: a meta-analysis. Eur Radiol. 2014;24(3):595-602.

14. Bernardi D, Caumo F, Macaskill P, et al. Effect of integrating 3D-mammography (digital breast tomosynthesis) with 2D-mammography on radiologists' true-positive and false-positive detection in a population breast screening trial. Eur J Cancer. 2014;50(7): 1232-1238.
15. Skaane P, Bandos AI, Gullien R, et al. Comparison of digital mammography alone and digital mammography plus tomosynthesis in a population-based screening program. Radiology. 2013;267(1):47-56.

16. Caumo F, Bernardi $D$, Ciatto $S$, et al. Incremental effect from integrating 3D-mammography (tomosynthesis) with 2D-mammography: increased breast cancer detection evident for screening centres in a populationbased trial. Breast. 2014;23(1):76-80.

17. Houssami N, Macaskill P, Bernardi D, et al. Breast screening using 2D-mammography or integrating digital breast tomosynthesis (3D-mammography) for single-reading or double-reading - evidence to guide future screening strategies. Eur J Cancer. 2014;50(10):1799-1807.

18. Lee CI, Lehman CD. Digital breast tomosynthesis and the challenges of implementing an emerging breast cancer screening technology into clinical practice. J Am Coll Radiol. 2013;10(12):913-917.

19. Pisano ED, Parham CA. Digital mammography, sestamibi breast scintigraphy, and positron emission tomography breast imaging. Radiol Clin North Am. 2000;38(4):861-869, x.

20. Hendricks ER, Pisano ED, Averbulch A, et al. Comparison of acquisition parameters and breast dose in digital mammography and screen-film mammography in the American College of Radiology Imaging Network digital mammographic imaging screening trial. AJR Am J Roentgenol. 2010;194(2):362-369.

21. Bloomquist AK, Yaffe MJ, Pisano ED, et al. Quality control for digital mammography in the ACRIN DMIST trial: part I. Med Phys. 2006;33(3):719-736.

22. Yaffe MJ, Bloomquist AK, Mawdsley GE, et al. Quality control for digital mammography: part II. Recommendations from the ACRIN DMIST trial. Med Phys. 2006;33(3):737-752.

23. Hauge IHR, Pedersen K, Sanderud A, Hofvind S, Olerud HM Patient doses from screen-film and full-field digital mammography in a population-based screening programme. Radiat Prot Dosimetry. 2012;148(1):65-73.

24. Aslund M, Cederström B, Lundqvist M, Danielsson M. Scatter rejection in multislit digital mammography. Med Phys. 2006;33(4):933-940.

25. Cole EB, Toledano AY, Lunqvist M, Pisano ED. Comparison of radiologist performance with photon-counting full-field digital mammography to conventional full-field digital mammography. Acad Radiol. 2012;19(8):916-922.

26. McCullagh JB, Baldelli P, Phelan N. Clinical dose performance of full-field digital mammography in a breast screening programme. $\mathrm{Br} J$ Radiol. 2011;84(1007):1027-1033.

27. Baldelli P, McCullagh J, Phelan N, Flanagan F. Comprehensive dose survey of breast screening in Ireland. Radiat Prot Dosimetry. 2011;145(1):52-60.

28. Keavey E, Phelan N, O'Connell AM, et al. Comparison of the clinical performance of three digital mammography systems in a breast cancer screening programme. Br J Radiol. 2012;85(1016):1123-1127.

29. Schell MJ, Yankaskas BC, Ballard-Barbash R, et al. Evidence-based target recall rates for screening mammography. Radiology. 2007; 243(3):681-689.

30. American College of Radiology (ACR). ACR BI-RADS ${ }^{\circledR}$ mammography. In: Sickles EA, D'Orsi CJ, Bassett LW, et al, editors. ACR BI-RADS Atlas: Breast Imaging Reporting and Data System. 5th ed. Reston (VA): American College of Radiology; 2013.

31. Stomper PC, D’Souza DJ, DiNitto PA, Arredondo MA. Analysis of parenchymal density on mammograms in 1353 women 25-79 years old. AJR Am J Roentgenol. 1996;167(5):1261-1265.

32. Mandelson MT, Oestreicher N, Porter PL, et al. Breast density as a predictor of mammographic detection: comparison of intervaland screen-detected cancers. J Natl Cancer Inst. 2000;92(13): 1081-1087.

33. Kolb TM, Lichy J, Newhouse JH. Comparison of the performance of screening mammography, physical examination, and breast US and evaluation of factors that influence them: an analysis of 27,825 patient evaluations. Radiology. 2002;225(1):165-175.

34. Boyd NF, Gua H, Martin LJ, et al. Mammography density and the risk and detection of breast cancer. $N$ Engl J Med. 2007;356(3):227-236. 
35. Buist DS, Porter PL, Lehman C, Taplan SH, White E. Factors contributing to mammography failure in women aged 40-49 years. J Natl Cancer Inst. 2004;96(19):1432-1440.

36. Roubidoux MA, Bailey JE, Wray LA, Helvie MA. Invasive cancers detected after breast cancer screening yielded a negative results: relationship of mammographic density to tumor prognostic factors. Radiology. 2004;230(1):42-48.

37. Kopans DB. Digital breast tomosynthesis from concept to clinical care. AJR Am J Roentgenol. 2014;202(2):299-308.

38. Niklason LT, Christian BT, Niklason LE, et al. Digital tomosynthesis in breast imaging. Radiology. 1997;205(2):399-406.

39. Feng SS, Sechopoulos I. Clinical digital breast tomosynthesis system: dosimetric characterization. Radiology. 2012;263(1):35-42.

40. Förnvik D, Andersson I, Svahn T, Timberg P, Zackrisson S, Tingberg A. The effect of reduced breast compression in breast tomosynthesis: human observer study using clinical cases. Radiat Prot Dosimetry. 2010;139(1-3):118-123.

41. Kopans DB. A new era in mammography screening. Radiology. 2014;271(3):629-631.

42. Waldherr C, Cerny P, Altermatt HJ, et al. Value of one-view breast tomosynthesis versus two-view mammography in diagnostic workup of women with clinical signs and symptoms and in women recalled from screening. AJR Am J Roentgenol. 2013;200(1):226-231.

43. Gur D, Abrams GS, Chough DM, et al. Digital breast tomosynthesis: observer performance study. AJR Am J Roentgenol. 2009;193(2): 586-591.

44. Michell MJ, Iqbal A, Wasan RK, et al. A comparison of the accuracy of film-screen mammography, full-field digital mammography, and digital breast tomosynthesis. Clin Radiol. 2012;67(10):976-981.

45. Ciatto S, Houssami N, Bernardi D, et al. Integration of 3D digital mammography with tomosynthesis for population breast-cancer screening (STORM): a prospective comparison study. Lancet Oncol. 2013;14(7):583-589.

46. Blue Cross and Blue Shield of Alabama. Digital breast tomosynthesis. 2013. https://www.bcbsal.org/providers/policies/final/252.pdf. Accessed May 29, 2014

47. Spangler ML, Zuley ML, Sumkin JH, et al. Detection and classification of calcifications on digital breast tomosynthesis and 2D digital mammography: a comparison. AJR Am J Roentgenol. 2011;196(2): 320-324.

48. Zuley ML, Guo B, Catullo VJ, et al. Comparison of two-dimensional synthesized mammograms versus original digital mammograms alone and in combination with tomosynthesis images. Radiology. 2014;271(3):664-671.

49. Haas BM, Kalra V, Geisel J, Raghu M, Durand M, Philpotts LE. Comparison of tomosynthesis plus digital mammography and digital mammography alone for breast cancer screening. Radiology. 2013;269(3):694-700
50. Luparia A1, Mariscotti G, Durando M, et al. Accuracy of tumour size assessment in the preoperative staging of breast cancer: comparison of digital mammography, tomosynthesis, ultrasound and MRI. Radiol Med. 2013;118(7):1119-1936.

51. Noroozian M, Hadjiiski L, Rahnama-Moghadam S, et al. Digital breast tomosynthesis is comparable to mammographic spot views for mass characterization. Radiology. 2012;262(1):61-68.

52. Hendrick RE. Radiation doses and cancer risks from breast imaging studies. Radiology. 2010;257(1):246-253.

53. Gur D, Zuley ML, Anello MI, et al. Dose reduction in digital breast tomosynthesis (DBT) screening using synthetically reconstructed projection images: an observer performance study. Acad Radiol. 2012;19(2):166-171.

54. Skaane P, Bandos AI, Eben EB, et al. Two-view digital breast tomosynthesis screening with synthetically reconstructed projection images: comparison with digital breast tomosynthesis with full-field digital mammographic images. Radiology. 2014;271(3):655-663.

55. Chan HP, Wei J, Sahiner B, et al. Computer-aided detection system for breast masses on digital tomosynthesis mammograms: preliminary experience. Radiology. 2005;237(3):1075-1080.

56. Dromain C, Balleyguier C, Adler G, Garbay JR, Delaloge S. Contrast-enhanced digital mammography. Eur J Radiol. 2009;69(1): 34-42.

57. Jong RA, Yaffe MJ, Skarpathiotakis M, et al. Contrast-enhanced digital mammography: initial clinical experience. Radiology. 2003;228(3):842-850.

58. Dromain C, Balleyguier C, Muller S, et al. Evaluation of tumor angiogenesis of breast carcinoma using contrast-enhanced digital mammography. AJR Am J Roentgenol. 2006;187(5):W528-W537.

59. Diekmann F, Bick U. Breast tomosynthesis. Semin Ultrasound CT MR. 2011;32(4):281-287.

60. Dromain C, Thibault F, Muller S, et al. Dual-energy contrast-enhanced digital mammography: initial clinical results. Eur Radiol. 2011;21(3): 565-574.

61. Lewin JM, Isaacs PK, Vance V, Larke FJ. Dual-energy contrast-enhanced digital subtraction mammography: feasibility. Radiology. 2003;229(1):261-268.

62. Jochelson MS, Dershaw DD, Sung JS, et al. Bilateral contrast-enhanced dual-energy digital mammography: feasibility and comparison with conventional digital mammography and MR imaging in women with known breast carcinoma. Radiology. 2013;266(3):743-751.

63. Chen SC, Carton AK, Albert M, Conant EF, Schnall MD, Maidment AD. Initial clinical experience with contrast-enhanced digital breast tomosynthesis. Acad Radiol. 2007;14(2):229-238.

64. Schmitzberger FF, Fallenberg EM, Lawaczeck R, et al. Development of low-dose photon-counting contrast-enhanced tomosynthesis with spectral imaging. Radiology. 2011;259(2):558-564.
International Journal of Women's Health

\section{Publish your work in this journal}

The International Journal of Women's Health is an international, peerreviewed open-access journal publishing original research, reports, editorials, reviews and commentaries on all aspects of women's healthcare including gynecology, obstetrics, and breast cancer. The manuscript management system is completely online and includes

\section{Dovepress}

a very quick and fair peer-review system, which is all easy to use. Visit http://www.dovepress.com/testimonials.php to read real quotes from published authors. 